TAP CHÍ KHOA HỌC ĐẠI HỌC TÂN TRÀO
ISSN: $2354-1431$

\title{
NHÂN VẬT NŨ̃ TRONG TIỂU THUYẾT CỦA KHÁI HƯNG DƯớI GÓC NHÌN NŨ QUYỀN LUẬN
}

(Khảo sát qua Hồn bướm mo tiên, Đời mưa gió, Nưa chùng xuân)

\author{
Phạm Thị Thiểm ${ }^{1 *}$ \\ ${ }^{1}$ Ban Tuyên giáo, Bộ Giáo dục và đào tạo \\ *Email: ptthiem@moet.gov.vn
}

\section{Thông tin bài viết}

Ngày nhận bài:

27/8/2020

Ngày duyệt đăng:

20/9/2020

Tù khóa:

"Nũ quyền", "tiểu thuyết",

"Tụ lục văn đoàn”, "Khái

Hung”, "hình tuợng ngưòi phụ nü"

\section{Tóm tắt}

Dùng lý thuyết phê bình nữ quyền để khám phá hình tượng người phụ nữ, bài viết chỉ ra những nét mới, độc đáo trong cách nhìn nhận và xây dựng nhân vật trong tiểu thuyết của Khái Hưng. Không chỉ ngợi ca vẻ đẹp ngoại hình, nhà văn còn rất trân trọng những nét đẹp tâm hồn của các cô "gái mới”. Khác với những người phụ nữ truyền thống đại diện cho luân lý và đạo đức phong kiến, họ không ngần ngại thể hiện khát khao và đòi hỏi chính đáng để luôn được sống là mình và cho mình, nhất là trong tình yêu và hôn nhân. Bài viết hi vọng sẽ góp một phần nhỏ bé vào việc đánh giá, "nhìn nhận lại” hiện tượng "Tự lực văn đoàn" nói chung, tiểu thuyết của Khái Hưng nói riêng.

\section{1. Đặt vấn đề}

Bắt nguồn từ chế độ phong kiến, tư tưởng "trọng nam khinh nữ" không chỉ gây tình trạng bất bình đẳng giới trầm trọng mà còn là nguồn cơn của biết bao tấn bi kịch đối với người phụ nữ. Như một lẽ tất yếu, ngọn lửa đấu tranh giành quyền bình đẳng cho một nửa thế giới đã bùng lên mạnh mẽ ở khắp nơi với tên gọi Nữ quyền luận - Chủ nghĩa nữ quyền. Cuộc đấu tranh ấy diễn ra trên nhiều lĩnh vực, trong đó có văn học. Ở Việt Nam, vấn đề nữ quyền luận tuy mới được đặt ra trong thời gian gần đây với số lượng công trình nghiên cứu còn khá ít ỏi, nhưng thu hút sự quan tâm của đông đảo giới nghiên cứu. Vì vậy, tìm hiểu, đánh giá về vấn đề nữ quyền luận trong các sáng tác văn học là việc làm hết sức cần thiết.

\section{Nội dung}

2.1. Tiểu thuyết Tự lực văn đoàn và vấn đề "nhận thức lại"

Nhìn lại quá trình hiện đại hóa văn học Việt Nam, giai đoạn 1930-1945 diễn ra vô cùng quyết liệt quá trình hiện đại hóa văn học với sự nở rộ của nhiều khuynh hướng và trào lưu văn học. Cùng với phong trào Thơ mới, tiểu thuyết 1930 - 1945 (với hai dòng chủ đạo là tiểu thuyết lãng mạn (tiêu biểu là Tự lực văn đoàn) và tiểu thuyết hiện thực) đã mở ra một thời kỳ rực rỡ huy hoàng trong văn học dân tộc - một thời kỳ phát triển đến đỉnh cao của thể loại với nhiều tác phẩm xuất sắc. Mặc dù vậy, khi nhìn lại lịch sử nghiên cứu, nếu những đánh giá về tiểu thuyết hiện thực đã có được sự nhất quán, thống nhất ngay từ đầu thì việc định giá tiểu thuyết lãng mạn lại tương đối phức tạp với những nhận định nhiều khi trái chiều. Đã có nhiều công trình nghiên cứu về tiểu thuyết Tự lực văn đoàn - khen cũng nhiều mà chê cũng không ít. Thậm chí, có những lúc, giai đoạn văn học này còn bị phủ định. Bởi vậy, sau gần một thế kỉ, vấn đề "nhận thức lại" để tìm ra những cách tiếp nhận khác đã trở thành một hướng đi mới trong nghiên cứu văn học lãng mạn ở Việt Nam. Một loạt tác phẩm của Nhất Linh, Khái Hưng, Hoàng Đạo, Thạch Lam... được in lại và giới thiệu từ những góc nhìn mới. Tự lực văn đoàn được đánh giá như một nhân tố tích 
cực, góp phần đổi mới tư duy nghệ thuật tiểu thuyết và thi pháp thể loại. Ngay từ khi mới ra đời, Tự lực văn đoàn đã đề ra tôn chỉ hoạt động: "lúc nào cũng trẻ, cũng yêu đời, có chí phấn đấu và tin ở sự tiến bộ". Tư tưởng ấy được thể hiện rất thành công trong những tác phẩm được viết bằng bút pháp mềm mại và điêu luyện của Khái Hưng. Với Khái Hưng, viết văn như là một cách để chống lại lễ giáo phong kiến hà khắc và đòi hỏi hạnh phúc cá nhân cho con người. Để đạt được điều đó, ông và các nhà văn của Tự lực văn đoàn đã xây dựng hình ảnh những người phụ nữ truyền thống và hiện đại trong mối quan hệ xung đột gay gắt, từ đó làm nổi bật vẻ đẹp của những cô gái "mới”. Họ không chỉ có sức hấp dẫn về ngoại hình mà còn luôn mang trong mình khát khao sống mãnh liệt, khát khao được là chính mình, được tự do trong tình yêu và hôn nhân.

Không thể phủ nhận những thành tựu đáng trân trọng của giới nghiên cứu về tiểu thuyết Tự lực văn đoàn nói chung, nhân vật nữ trong tiểu thuyết của Khái Hưng nói riêng. Qua tìm hiểu những nghiên cứu đó, chúng tôi đã tiếp thu nhiều luận điểm sâu sắc, có giá trị khoa học mang tính chất gợi dẫn quan trọng giúp chúng tôi triển khai đề tài này. Nhưng cũng phải khẳng định rằng, phần lớn các công trình nghiên cứu dừng lại ở việc tiếp cận hình tượng người phụ nữ dưới góc nhìn thi pháp và nhìn một cách tổng thể, cho đến thời điểm này, chưa có công trình nghiên cứu tiếp cận từ lý thuyết phê bình nữ quyền. Thiết nghĩ, đây thực sự là một hướng đi mới, phù hợp, có triển vọng, có thể mang đến những phát hiện mới mẻ về những vấn đề vốn được xem là xưa cũ.

2.2. Hình tượng người phụ nữ trong tiểu thuyết Khái Hưng dưới lăng kính nữ quyền luận

Khái Hưng sáng tác dồi dào, phong phú với niềm say mê và giàu nghị lực. Qua 15 năm cầm bút, Khái Hưng để lại 12 tiểu thuyết, trong đó có một tiểu thuyết viết chung với Nhất Linh và rất nhiều truyện ngắn, kịch... Trong phạm vi khảo sát của đề tài, chúng tôi chỉ tập trung vào 3 tiểu thuyết được xem là tiêu biểu nhất của Khái Hưng, đó là: Hồn buớm $m o$ tiên (1933), Đời mưa gió (viết chung với Nhất Linh, 1937) và Nưa chùng xuân (1938).

Không phải ngẫu nhiên mà số lượng nhân vật nữ trong các tiểu thuyết này lại nhiều đến thế. Hầu hết nhân vật chính trong các tiểu thuyết đều do nhân vật nữ đảm nhiệm. Có khi, số lượng nhân vật nữ nhiều hơn nhân vật nam. Điều đó cho thấy sự quan tâm đặc biệt của nhà văn đối với nữ giới. Nhà văn khao khát khám phá vẻ đẹp mới ở nhân vật, khao khát thể hiện những diễn biến mới trong tâm lý cũng như những suy tư, trăn trở về cuộc đời, thân phận của họ, qua đó, giúp nữ giới xác lập được tiếng nói riêng, mạnh mẽ, đầy kiêu hãnh.

\subsection{1. Ý thức sâu sắc về vẻ đẹp tự thân}

Trước hết, các nhân vật nữ đều được Khái Hưng nhấn mạnh ở phương diện ngoại hình. Lan, Mai, Liên, Tuyết... đều là những người phụ nữ đẹp, hấp dẫn. Vẫn là vẻ đẹp của mái tóc, của làn da, của đôi mắt, nụ cười, dáng vẻ..., những vẻ đẹp thể hiện đặc trưng nữ giới vô cùng rõ nét nhưng độc đáo là ở chỗ, nhà văn thường miêu tả vẻ đẹp ấy trong những khung cảnh thiên nhiên thơ mộng, trữ tình, đồng thời luôn thể hiện cái nhìn trân trọng dành cho họ.

Có thể thấy, văn học từ xưa đến nay đã dành rất nhiều bút mực để miêu tả vẻ đẹp thân thể của người phụ nữ. Với tư duy hồn nhiên và chịu ảnh hưởng của nền văn hóa Mẫu hệ, các nghệ sĩ dân gian với cái nhìn đầy thiện cảm đã tạo nên những phác thảo đơn sơ về chân dung người phụ nữ: "Cổ tay em trắng như ngà/ Đôi mắt em liếc như là dao cau/ Miệng cười như thể hoa ngâu/ Cái khăn đội đầu như thể hoa sen". Mỗi người đẹp một vẻ. Có người đẹp nhờ mái tóc bồng bềnh, đôi chân mày cong tựa vầng trăng non: "Chân mày vầng nguyệt có duyên/ Tóc mây gợn sóng đẹp duyên tơ hồng". Có người lại đẹp nhờ ánh mắt, khuôn mày biết nói: "Những người con mắt là răm/ Đôi mày lá liễu đáng trăm quan tiền".

Đến văn học trung đại, sự kiềm tỏa của lễ giáo phong kiến hà khắc cùng chế độ nam quyền khiến các tác giả dường như né tránh miêu tả vẻ đẹp thân thể của người phụ nữ, hoặc có được đề cập cũng là theo những khuôn mẫu định sẵn, kiểu như: "Khuôn trăng đầy đặn, nét ngài nở nang" (Truyện Kiều Nguyễn Du). Hệ giá trị thẩm mĩ trung đại đánh giá người phụ nữ theo công thức: "Công, Dung, Ngôn, Hạnh” mà chữ Dung luôn được xếp sau. Người phụ nữ sống khép mình theo lễ giáo: "Nam nữ thụ thụ bất thân". Vậy nên, những miêu tả đầy táo bạo, phồn thực như nữ sĩ Hồ Xuân Hương thời đó được xem như là một sự nổi loạn: "Mùa hè hây hẩy gió nồm đông/ Thiếu nữ nằm chơi quá giấc nồng/ Lược trúc biếng cài trên mái tóc/ Yếm đào trễ xuống dưới nương long/ Đôi gò bồng đảo sương còn ngậm/ Một lách đào nguyên suối chửa thông" (Thiếu nũ ngủ ngày - Hồ Xuân Hương) 
Sang thế kỉ XX, dưới ảnh hưởng của tư tưởng phương Tây, cái nhìn về người phụ nữ đã cởi mở hơn rất nhiều. Trùng quang tâm sư (Phan Bội Châu), Tố tâm (Hoàng Ngọc Phách), Giọt lệ sông Huoong (Tam Lang Vũ Đình Chí) là những tác phẩm đã xây dựng thành công hình tượng người phụ nữ nhưng đó vẫn là những mẫu hình phụ nữ truyền thống.

Chỉ đến khi Tự lực văn đoàn xuất hiện, khi người phụ nữ xuất hiện trong văn học với tư cách là một con người cá nhân mang theo trong mình những khát vọng tự do mạnh mẽ mới thực sự được tôn vinh và được nhìn nhận một cách thỏa đáng. Vẻ đẹp thân xác của người phụ nữ được các nhà văn miêu tả cụ thể, trực diện với tất cả những nét vẽ trần thế nhất, gợi cảm nhất bởi các nhà văn quan niệm: vẻ đẹp thân xác mới chính là thước đo, là tiêu chuẩn để đánh giá con người. Đây là một quan điểm thẩm mĩ hoàn toàn mới mẻ của thời đại. Điều này giúp độc giả có thể cảm nhận được vẻ đẹp của nhân vật như họ đang đứng ngay trước mặt.

Đọc tiểu thuyết của Khái Hưng, chúng tôi nhận thấy Khái Hưng đặc biệt chú ý tới sự trẻ trung và bản sắc giới tính của người phụ nữ. Lan trong Hồn buoóm $m o$ tiên xinh đẹp, hiền hòa, dịu dàng và nữ tính đến nỗi Ngọc luôn muốn họa nàng thành tranh để được thỏa sức ngắm nhìn. Vì vậy, dù màn cải trang nam của Lan hoàn hảo đến đâu đi chăng nữa thì những vẻ đẹp nữ tính trong nàng vẫn toát ra bên ngoài khiến Ngọc ngay từ lần đầu gặp mặt đã không thôi nghi ngờ: "Quái lạ, sao vùng nhà quê lại có người đẹp đến thế, nước da trắng mát, tiếng nói dịu dàng, trong trẻo như tiếng con gái” [3, tr10]. Khái Hưng không chỉ có biệt tài sử dụng ngôn ngữ mà còn có năng lực hội họa tinh tế khiến bức họa chân dung Lan hiện lên sống động, hút hồn: từ những vẻ đẹp bên ngoài của "làn da trắng mát", "hai má đỏ hồng" đến sự tươi mới, trẻ trung bên trong của một tâm hồn cô gái mới lớn. Chính những vẻ đẹp đó đã hút hồn Ngọc, khiến Ngọc ngày đêm thẫn thờ tưởng nhớ: "Tôi xin thú thực với ni cô rằng, tôi yêu ni cô, tôi yêu ngay từ lúc còn tưởng ni cô là trai. Ni cô là một người thông minh, đĩnh ngộ, xinh đẹp như thế, ai lại không yêu được" [3, tr82].

Nếu như Lan trong Hồn buớm mo tiên hiện lên với vẻ đẹp nữ tính, trong sáng và đầy thánh thiện dưới con mắt si tình của riêng mình $\mathrm{Ngọc} \mathrm{thì} \mathrm{vẻ} \mathrm{đẹp}$ của Mai trong Nứa chùng xuân lại có thể làm đắm say không biết bao người. Với "nước da trắng, quầng mắt sâu hoắm làm tăng vẻ rực rỡ long lanh của hai con ngươi sáng dịu... Mặt trái xoan, hai con mướt ướt như hai ngôi sao lấp lánh sau làn mây mỏng” [3, tr95], Mai thực sự đã chiếm được cảm tình của Lộc ngay từ lần đầu gặp gỡ: "Mai cầm cành đào cài vào mái tóc, quả nhỏ và lá rũ xuống trán, xuống tai, khiến Lộc đứng ngẩn người ra ngắm ngía, tấm tắc khen: Trông em đẹp như thiên nga" [3, tr181]. Bác sĩ Minh thì quả quyết: "Mai đẹp lắm, đẹp ít người sánh kịp" [3, tr263]. Còn với họa sĩ Bạch Hải, Mai là một kiểu mẫu lí tưởng: "Tôi đi tìm kiểu mẫu đã nhiều, song chưa gặp được ai có cái nhan sắc như cô” [3, tr270]. Thậm chí, những người không dành cho Mai chút yêu mến nào cũng chẳng thể phủ nhận vẻ xinh đẹp của Mai. Bà Án, mẹ Lộc, người cương quyết tìm mọi cách để phá tan hạnh phúc gia đình Mai Lộc cũng phải thốt lên sửng sốt khi gặp Mai: "Mai đẹp lắm, đẹp dịu dàng, đôn hậu" $[3, \operatorname{tr} 316]$. Còn bà Hàn không bằng lòng mua nhà cho Mai chỉ vì "Mai đẹp quá" [3, tr150]. Khái Hưng nhiều lần lặp đi lặp lại hình ảnh Mai với nụ cười tươi thắm nở trên môi như muốn nhấn mạnh nét đẹp thân thiện, tươi trẻ và sức cuốn hút lạ kì: "Cái nụ cười của cô vẫn còn nở trên cặp môi thắm" [3, tr123], "Cô đi thoăn thoắt lúc cặp môi thắm với gió xuân" $[3, \operatorname{tr} 131]$ ”, "Nụ cười lạ, nở trên cặp môi đỏ thắm" $[3, \operatorname{tr} 132] \ldots$

Lan và Mai xinh đẹp là thế nhưng quyến rũ nhất phải kể đến Tuyết trong Đời mura gió. Với Tuyết, Khái Hưng mạnh dạn khắc họa những nét đẹp mang đầy yếu tố sắc dục. Đó là vẻ đẹp của "cặp mắt sắc sảo" [4, tr53], "hai má đỏ hây" [4, tr56], "cái tay trắng muốt, mềm mại" $[4$, tr69]. "Tuyết vừa nói vừa liếc mắt long lanh hoạt động nhìn Chương một cách rất tình tứ. Cặp môi bôi sáp đỏ hình trái tim... một nụ cười làm hai lúm đồng tiền ở hai má mơn mởn như tuyết trái đào Lạng Sơn chín hồng mới hái” [4, tr33]. Dường như bị mê hoặc bởi Tuyết, Chương đã không ít lần ví Tuyết như "tố nữ", như "tiên giáng trần". "Ai đã đến chơi nhà Chương cũng khó lòng ghét được Tuyết... Vì Tuyết khôn khéo mà lại thông minh... Nàng lại là người rất thiệp, thạo đủ ngón lịch sự phong lưu" [4, tr103-104].

Điều đặc biệt là những nhân vật nữ trong tiểu thuyết của Khái Hưng không chỉ xinh đẹp mà họ còn rất ý thức về vẻ đẹp tự thân ấy của mình, thậm chí ý thức việc dùng phấn son để được lộng lẫy, xinh đẹp hơn. Đây là điều mà trong văn học truyền thống trước giờ chưa từng có. Tuyết thường ăn vận rất thành thị. Mỗi khi ra ngoài Tuyết không quên trang điểm bởi khi trang điểm xong và trông mình trong 
gương, Tuyết "thấy nhan sắc thay đổi hẳn... vẻ mặt tươi tắn, đôi má hồng đào, cặp mắt sáng quắc" [4, tr151]. Có lần "Chương bĩu môi bảo Tuyết: "Cô có thấy cô dơ dáng dại hình không?" Tuyết đứng dậy ngắm trước gương bầu dục, rồi trở lại chỗ cũ trả lời: "Không anh ạ. Hình dáng em vẫn xinh như thường" [4, tr57]. Tuyết tự thú nhận: "Trời phú cho em một khối óc tốt tươi và một trái tim dễ cảm nên em thấy ai, em cũng tưởng người ta yêu em và em cũng muốn yêu người ta" $[4$, tr86]. Còn Mai, Mai thấy mình "trẻ lắm... mới 19 cái xuân xanh.... Mai cũng biết Mai trẻ. Mai đẹp... Chỉ ngắm cái nét mặt khinh bỉ của mấy chị em con bác Phán, Mai cũng đủ hiểu rằng Mai đẹp. Mai lại nhớ khi ở trên xe hỏa, có một công tử vận tây đã lưu ý đến Mai, làm Mai phải bẽn lẽn cúi mặt" [3, tr112]. Bằng việc bứt phá ra khỏi thứ văn đạo mạo truyền thống, thay vào đó là cách miêu tả tự nhiên về những nét đẹp thân thể của người phụ nữ, Khái Hưng đã đem đến cho văn học những nét chấm phá vô cùng mới mẻ nhằm tôn vinh giá trị của người phụ nữ.

2.2.2. Khát khao tự do, quyết liệt đấu tranh cho tình yêu và hạnh phúc

Không chỉ khám phá vẻ đẹp ngoại hình của các nhân vật nữ, Khái Hưng còn rất dụng công khắc họa vẻ đẹp tâm hồn họ. Nhà văn không ca ngợi vẻ đẹp của trinh tiết, đạo đức ở những người phụ nữ như các nhà văn trước đây mà chú trọng ngợi ca những phẩm chất mới mẻ, thể hiện rõ ý thức cá nhân của nhân vật.

Trước hết, họ đều là những người phụ nữ thông minh, có học thức, rất bản lĩnh, quyết đoán và luôn mong muốn được chủ động lựa chọn số phận của mình. Họ khát khao được hưởng hạnh phúc, khát khao tự do trong tình yêu và hôn nhân. Vậy nên, ở những tình huống cần phải lựa chọn giữa trách nhiệm bổn phận và đời sống cá nhân tự do, các nhân vật nữ đã phản kháng dữ dội, quyết liệt để bảo vệ mình và những người thân yêu.

Không chiều theo sự sắp đặt của gia đình, Lan trốn vào tu trên chùa Long Giáng, xa lánh cõi trần. Sự phản ứng mạnh mẽ của Lan không chỉ thể hiện ý thức rõ rệt của cô về quyền tự do cá nhân mà còn là minh chứng hùng hồn chứng minh rằng: người phụ nữ hiện đại hoàn toàn có quyền bác bỏ những quy tắc, luật lệ xưa cũ trói buộc con người. Còn Mai, cô xuất thân trong gia đình trí thức nhưng khi cha mất, gia tài dần khánh kiệt, một mình cô cáng đáng gia đình, nuôi em ăn học. Cô thà bán nhà chứ nhất quyết không làm lẽ ông Hàn. Bà Án thuyết phục Lộc rời xa
Mai không được, quay sang nịnh nọt Mai về làm lẽ của Lộc, Mai cũng một mực từ chối: "Con không thể nào yêu chồng người khác được. Thà con chết còn hơn đi lấy lẽ. Lương tâm con không cho con làm những điều vô nhân đạo như thế" [3, tr223]. Mai chấp nhận xa Lộc, chấp nhận hi sinh tình yêu, chấp nhận hy sinh hạnh phúc ngay giữa "nửa chừng xuân" để đối mặt với lam lũ, vất vả ở đời chứ không chấp nhận là kẻ thứ ba xen vào giữa hạnh phúc của người khác. Sự mạnh mẽ, dứt khoát của Lan, của Mai khác hẳn với hình ảnh những người phụ nữ trong văn học truyền thống. Sự mạnh mẽ, dứt khoát quyết liệt ây chỉ có thể có ở những người phụ nữ có ý chí vượt lên trên những kiềm tỏa trói buộc mình, chủ động thay đổi cuộc đời mình, tự giải thoát mình khỏi những tư tưởng "thiên định" về "phận má hồng", về "nỗi truân chuyên "tiền định". Đó là những người phụ nữ mạnh mẽ, quyết đoán, bản lĩnh, dám làm, dám chịu, không dễ dàng thỏa hiệp cũng như tự biến mình thành kẻ lệ thuộc.

Mạnh mẽ hơn cả, cá tính hơn cả, dám là mình hơn cả phải kể đến cô Tuyết trong Đời mura gió. Tuyết xác lập cho mình một lẽ sống riêng: "Không tình, không cảm, chỉ coi lạc thú trên đời như một vị thuốc trường sinh" [4, tr73]. Vì vậy, cô luôn đi theo tiếng gọi của lạc thú, chẳng ai có thể điều khiển hay giữ được chân cô. Tuyết thú nhận: "Em đã như con chim lạc đàn, nay đây mai đó” [4, tr84], "cái đời khốn nạn ấy, thật ra em đã tự dấn mình vào, em nhận như thế chứ không dám chối cãi, mà em không hề oán trách ai" [4, tr85], "Em đã thề với em rằng bao giờ e cũng sẽ là của em, từ thể phách cho chí tâm hồn. Em không sao làm vợ, nghĩa là làm vật sở hữu của ai được" $[4, \operatorname{tr} 137]$.

Đặt vào giữa thế giới các nhân vật trong lịch sử văn học Việt Nam trước đó, Tuyết như thể là một kẻ lạc đàn - một người từ một thế giới khác đến: suy nghĩ khác, hành xử khác, sống khác. Cô gái ấy yêu thì dám nói là yêu, thậm chí chủ động đấu tranh để giành lấy người mà mình yêu. Câu nói cửa miệng của Tuyết: "như thường" phần nào thể hiện bản ngã, sự tự tin của một "gái mới" thản nhiên khẳng định cá tính, bất chấp ai nghĩ gì, nói gì. Sự đối lập giữa Tuyết và Thu cùng thái độ của Chương cũng cho thấy thị hiếu thẩm mĩ của thời đại đã thay đổi: trước đây một cô gái như Thu mới là hoàn hảo (vị thế gia đình xứng đáng cho một cuộc hôn nhân môn đăng hộ đối, vẻ yểu điệu xinh tươi lại khép nép giữ gìn rất ra dáng con nhà nề nếp) nhưng nay, một cô gái như Tuyết mới thực sự hấp dẫn. Tuyết nhí nhảnh, trẻ trung, thẳng thắn và rất 
thực tế. Tuyết dám nói, dám làm, dám bộc lộ mình và dám chịu trách nhiệm về chính mình.

Cuộc hôn nhân không hạnh phúc với một người chồng ngu dốt trong một gia đình trưởng giả, cổ lỗ đã khiến Tuyết (Đời mura gió) quyết định bỏ nhà đi "theo giai". Tuyết phớt lờ mọi ánh mắt dè bỉu, đặt mình ra ngoài vòng luân lí, đạo đức, sống đời mưa gió miễn sao được tự do và được thỏa mãn nhu cầu thể xác. Gặp Chương, Tuyết tưởng như tìm được một vòng tay yêu thương yên bình. Nhưng không bằng lòng với cuộc sống tẻ nhạt, Tuyết không ít lần bỏ đi theo Văn, theo Giang, rồi lại tự tìm về với Chương. Lần trở lại cuối cùng, Tuyết vô cùng hối hận: "Nếu ta biết chàng yêu ta đến thế thì ta đừng đến nhà chàng có hơn không. Chàng sẽ mãi sống với hình ảnh không già của ta. Nhưng nay chàng đã trông thấy ta rồi, thì từ đây, ta sẽ không còn chiếm được một chỗ cỏn con trong tâm hồn chàng nữa" [4, tr215]. Thế mà một sớm mai thức giấc, Tuyết lại bỏ Chương đi. Đối với Tuyết, thà liều thân với một đời mưa gió, khổ sở, đê tiện còn hơn là sống lừa dối bên cạnh Chương. Tuyết cũng không thể sống mãi một kiếp buồn tẻ cùng vun đắp hạnh phúc đơn sơ, giản dị với người chồng học thức, nhân hậu bởi chính nó, luôn nhắc Tuyết rằng: địa vị của nàng vốn không phải ở đây. "Nàng như hiểu lờ mờ rằng, trừ những khoái lạc hàng ngày ra, nàng không nên hy vọng những hạnh phúc đâu đâu. Gia đình. Một người như nàng không có quyền tưởng tới gia đình" [4, tr174]. Người con gái ấy đã hoàn toàn tự do đến với Chương và cũng hoàn toàn tự do để ra đi. Vậy nên, hành động hủy đi kí ức, xé vứt vào lò sưởi những bức ảnh treo trên tường rồi đi biệt lại là minh chứng cho lòng tự trọng của Tuyết. Tuyết thực sự thấy mình nhơ nhuốc và không muốn quấy rối cuộc sống bình yên của Chương thêm lần nào nữa.

Nếu Tuyết sống hưởng lạc thì Mai, người phụ nữ mạnh mẽ, thanh cao và đức hạnh, hoàn toàn xứng đáng được hưởng hạnh phúc nhưng lại luôn nhận về mình phần thua thiệt, tự nguyện hi sinh cho em, cho chồng, cho con: "Trong nhân loại có một hạng người đa cảm đến nỗi thà chịu khổ còn hơn là đứng ngắm cái khổ của người khác.Vì thế, họ hay nghĩ đến sự hi sinh nọ, sự hi sinh kia" [3, tr16]. Mai chịu nhiều thua thiệt nhưng vẫn giữ cho mình một tình yêu trọn vẹn, chân thành dành cho Lộc và chưa từng rung động với bất cứ ai khác. Bởi với Mai, hi sinh là hạnh phúc. Phát hiện ra những phẩm chất mới của người phụ nữ nhưng Khái Hưng cũng nhận thấy rất rõ bản sắc giới tính nơi họ. Ẩn sau vẻ bề ngoài mạnh mẽ, quyết đoán vẫn là trái tim thổn thức, giàu yêu thương.

Kết thúc tác phẩm, những cô "gái mới” trong tiểu thuyết của Khái Hưng vẫn không nhận được hạnh phúc trọn vẹn bởi sợi dây của lễ giáo phong kiến vẫn không thôi kiềm tỏa họ, bởi cái mới tuy đã nhen nhóm nhưng còn yếu ớt, chưa đủ sức chống đỡ và chiến thắng cả một thành trì vững chãi của chế độ nam quyền và thần quyền. Lan vẫn đi tu. Mai nuôi con một mình, không danh chính ngôn thuận với Lộc. Tuyết thân tàn ma dại, bỏ Chương đi giữa những ngày Tết sum họp, ấm áp của mọi người. Nhưng thông qua cuộc đời của Lan, Mai, Tuyết, Khái Hưng đã xác lập những góc nhìn mới mẻ về người phụ nữ, thể hiện sự tôn vinh và trân trọng dành cho họ. Thậm chí, khi người đời có nhìn họ bằng ánh mắt đầy kì thị thì tác giả vẫn nhìn họ rất đỗi trìu mến. Phương, bạn thân của Chương bức xúc khi thấy đi đâu Chương cũng cho Tuyết đi cùng: "Ai lại thân danh một ông giáo mà mê một con đĩ, đi đâu cũng đưa nó đi theo như vợ" [4, tr99] thì Chương không ngại ngùng phản pháo: "Tuyết là người yêu của tôi, anh chỉ nên biết thế thôi. Vả đĩ, thì ai ai cũng đĩ, chỉ khác có một đằng đĩ với một người và một đằng đĩ với nhiều người" [4, tr99]. Với Chương, Tuyết như một cô gái thượng lưu và tử tế. Câu nói của Chương hay nói cách khác, đó cũng chính là tiếng nói xác lập tinh thần tôn trọng, đề cao quyền tự do cá nhân của Khái Hưng dành cho người phụ nữ, dù họ là ai, họ thuộc tầng lớp nào trong xã hội.

\section{Kết luận}

Kể từ khi ra đời đến nay, Tự lực văn đoàn đã trở thành tâm điểm chú ý của giới nghiên cứu văn học và sức sống ấy vẫn luôn mạnh mẽ cho tới ngày hôm nay. Đã có rất nhiều công trình nghiên cứu về Tự lực văn đoàn nói chung, hình tượng người phụ nữ trong tiểu thuyết của Khái Hưng nói riêng. Tuy nhiên, chưa có công trình nào dùng lý thuyết phê bình nữ quyền để nhìn nhận về hình tượng nhân vật vô cùng độc đáo này. Hướng đi mới thực sự đã đem đến những phát hiện vô cùng thú vị, đồng thời như là một "cách đọc khác" về Hồn bướm mo tiên, Nưa chùng xuân, Đời mura gió... Ở đây, nhà văn đã có sự phân biệt rõ ràng về hai loại nhân vật nữ trong tác phẩm của mình. Với những nhân nật nữ đại diện cho tư tưởng bảo thủ, tính nữ bị mờ hóa, con người chức năng, con người bổn phận được nhấn mạnh. Ngược lại, với những nhân vật nữ đại diện cho lối sống mới, tư tưởng mới, tính nữ được nhấn mạnh, vẻ đẹp hiện đại về hình thức được ngợi ca, khát vọng và phẩm chất mới được tô đậm. Thiết nghĩ, chính sự trân trọng mà Khái 
Hưng và những nhà văn cùng chí hướng với ông luôn dành cho những cô "gái mới” đã góp phần thổi bùng lên trong xã hội nhận thức mới về quyền sống, quyền được hạnh phúc và được khẳng định giá trị của người phụ nữ, điều mà các nhà văn ở giai đoạn trước chưa làm được.

\section{REFERENCES}

1. Do Hong Duc (2010), Female character in Nhat Linh and Khai Hung's novels, Doctoral thesis, Hanoi University of Education

2. Dao Duy Hiep (2008), Literary criticism from modern theory, Educational Publishing House
3. Khai Hung (2018), Hon buom mo tien, Nua chung xuan, Writers Association Publishing House, Hanoi

4. Nhat Linh, Khai Hung (2009), Rainy Life, Literature Publishing House, Hanoi

5. Phung Gia The, Tran Thien Khanh (2016), Literature and Women (Some theoretical and historical issues), International Publishing House, Hanoi

\section{THE WOMEN CHARACTERS IN KHAI HUNG' S NOVEL ON WOMEN'S RIGHT}

\begin{tabular}{l}
\hline Article info \\
\hline Recieved: \\
27/8/2020 \\
Accepted: \\
20/9/2020 \\
\hline
\end{tabular}

Keywords:

"Feminist", "novel", "Self-reliance union", "Khai Hung", "image of a woman"

\begin{abstract}
Using feminist criticism theory to discover the image of the woman, the article points out new and unique features in the way of looking at and building characters in Khai Hung's novels. Not only praising the beauty of the appearance but the writer also greatly appreciates the spiritual beauty of the "new women". Unlike traditional women who represent feudal morality and ethics, they do not hesitate to express a legitimate desire and demand to always live as themselves and for themselves, especially in their love and marriage. The article hopes to contribute a small part to the evaluation, "re-recognition" of the phenomenon of "Self-reliance union" in general, and Khai Hung's novels in particular.
\end{abstract}

